\title{
Thrombotic Thrombocytopenic Purpura
}

Chadi Saifan*, Rabih Nasr, Suchita Mehta, Pranab Sharma Acharya and Suzanne El-Sayegh

Division of Nephrology, Staten Island University Hospital, Staten Island, NY, USA

\section{Introduction}

Thrombotic microangiopathy comprises a spectrum of clinical and lab findings including microangiopathic hemolytic anemia, thrombocytopenia, and thrombosis of capillary and arterioles. Platelet and hyaline thrombi with complete or partial occlusion of these vessels are integral histopathological findings. These findings are seen irrespective of cause and organ involved. Pathogenesis and prognosis may differ for different forms of microangiopathy and clinical features often overlap.

Thrombotic angiopathy may be classified in a variety of ways based on various factors. A classical way of classification is dividing the spectrum of disease as Classical TTP, HUS or disease entity with severe ADAMTS 13 deficiency. Though the above classification favors dominant organ specific involvement, there is a large overlap in clinical features amongst these various groups making such distinctive classification of limited clinical significance. Though clinico-pathologically TTP and HUS overlap, both these entities appear to have distinct pathogenesis. Evidence shows a high incidence of ADAMTS13 deficiency in patients with clinically TTP but not HUS [1]. On the other hand familial and sporadic cases of HUS have been associated with deficiency of complement regulatory proteins, particularly factor $\mathrm{H}$ or membrane cofactor protein. Though TTP and HUS affect many of the same organ systems, the frequency with which they do so differs. Even histopathologic features of TTP and HUS are also distinct. Plasma exchange is highly effective for idiopathic TTP [2]. But is usually ineffective for sporadic HUS. Thus for a better understanding it seems reasonable to continue to distinguish these clinical entities while recognizing extensive overlap in clinical features. Classical TTP is associated with dominant neurological abnormalities. Renal involvement is common but with minimal instances of oliguric acute renal failure. This entity is usually associated with acquired autoantibodies that inhibit disintegrin and metalloprotease thrombospondin type 1 repeats (ADAMTS 13). Inherited deficiency of ADAMTS13, also known as Upshaw-Schulman syndrome, is a congenital form of TTP. Features of microangipathy with acute renal failure (oliguric/ anuric) is considered by some to represent HUS. HUS may be classified as Diarrhea associated HUS (also known as PRIMARY/ TYPICAL /EPIDEMIC HUS) due to identifiable enteric infection with Shigatoxin producing bacilli, most commonly Escherichia coli O157:H7 [3]. The Diarrhea NOT associated HUS (secondary/atypical/ sporadic HUS) comprises a group that is not associated with Shiga Toxin producing organism in patients without an obvious predisposing condition. In patients with severe ADAMTS 13 deficiency states both renal and neurological involvement is uncommon. On the other hand, some patients present with both neurological and renal involvement and are grouped into a broad TTP-HUS category.

There are other secondary causes of Micirangipathy. These include cancer, infections, stem cell transplant, chemotherapy and variety of drugs. In most of these cases ADAMTS13 levels are normal and management is basically aimed at correcting the primary cause.

\section{Epidemiology}

Before the plasma exchange era, survival of patients with TTP was only $10 \%$. When plasma exchange was reported to increase survival to $78 \%$, compared with $51 \%$ survival for patients treated with plasma infusion. The diagnosis of TTP became an indication for plasma exchange treatment. Oklahoma TTP-HUS Registry is a population based cohort registry of patients maintained since 1989 based on request received for plasma exchange treatment [4]. As the regustry is based on request for plasma exchange, many childeren with typical HUS are not included in the registry because they are not treated with plasma exchange. Because it is an all inclusive study with no patients excluded when plsma exchange request was received, incidence data was calculated in a recent paper by Terrel [5] ADAMSTS 13 activity and inhibitors of ADAMTS 13 activity are measured on all samples whose samples activity was less than $20 \%$. Severe ADAMTS13 deficinecy is defineed as activity less than $10 \%$ [5].

The whole registry is divided into three catagories: all patients with clinically suspected TTP-HUS, patients with idiopathic TTPHUS, and patients with severe ADAMTS-13 deficiency. ADAMSTS 13 activity and inhibitors of ADAMTS 13 activity are measured on all samples whose samples activity was less than $20 \%$. Severe ADAMTS13 deficinecy is defineed as activity less than $10 \%$ [6]. 10(6):

The age-sex-race standardized annual incidence rates were per

11.29 for all patients with clinically suspected TTP-HUS

4.46 For patients with idiopathic TTP-HUS

1.74 For patients with severe ADAMTS-13 deficiency $(<5 \%$ activity)

In all three categories, the incidence rates were greater for women and for patients with African ancestry. For patients with severe ADAMTS-13 deficiency ( $<5 \%$ activity), the age-sex standardized incidence rate ratio of blacks to non-blacks was 9.29. This greater incidence in black females is comparable with the increased risk of autoimmune disease within this subgroup of population.

Another recent review article estimated the incidence of acute ITP in children and adults as below: [7].

For children: 1.9 - 6.4 per 10(5) children/year.

For adults: 3.3 per 10(5) adults/year.

Regional variation may occur in incidence as these data were

*Corresponding author: Chadi Saifan, Division of Nephrology, Staten Island University Hospital, Staten Island, NY, USA, E-mail: chadisaifan@hotmail.com

Received February 01, 2012; Accepted February 20, 2012; Published February 26, 2012

Citation: Saifan C, Nasr R, Mehta S, Acharya PS, El-Sayegh S (2012) Thrombotic Thrombocytopenic Purpura. J Blood Disord Transfus S3:001. doi:10.4172/21559864.S3-001

Copyright: (C) 2012 Saifan C, et al. This is an open-access article distributed under the terms of the Creative Commons Attribution License, which permits unrestricted use, distribution, and reproduction in any medium, provided the original author and source are credited. 
mostly collected in Europe. Other evidence shows a peak incidence in the fourth decade and an association with obesity as well.

\section{Clinical Features}

The classical presentation of TTP is thrombocytopenia and hemolytic anemia with fragmentation red cells.

The clinical picture may be varying with $10-40 \%$ of patients complaining of an upper respiratory tract infection in preceding weeks. Patients may also present with nonspecific symptoms (malaise, fatigue, fever) lasting weeks that are unresponsive to symptomatic treatment. In this situation, the diagnosis could be confused until these non specific symptoms become severe or other organ system get involved. Neurologic involvement could range from headache and confusion to somnolence, seizures, aphasia, or coma. Symptoms may even fluctuate in severity that may be attributed to the repetitive formation and dissolution of microthrombi in the cerebral microvasculature.

Platelet counts may go below 20,000/mL, with muco-cutaneous bleeding. Prothrombin time, partial thromboplastin time, and fibrinogen levels are usually normal or only mildly altered. Fibrinogen degradation products occur in $50 \%$ of patients. Hematuria, proteinuria, granular or red cell casts, and mild azotemia may be the presenting features of TTP but anuria and renal failure are uncommon. Abdominal pain with or without pancreatitis, and electrocardiographic abnormalities have also been observed. Below is a recent chart from Oklahoma TTP-HUS Registry with clinical features of patients with severe ADAMTS13 deficiency. It is important to note that $31 \%$ of the patients had only minor symptoms (confusion, headache) whereas $34 \%$ had no neurologic abnormalities. Many developed new neurologic abnormalities during the course of treatment.

\section{Mechanism of Microvascular Thrombosis in TTP/ Pathogenesis}

\section{Pathogenesis of thrombosis in TTP}

The pathogenesis of thrombi formation is more clearly understood in models with severe ADAMTS13 deficiency whether due to genetic mutations or inhibitory autoantibodies.

Microvascular thrombi consist of von-willbrand factor and platelets. Understanding the interaction between vWF and platelet is crucial for knowing why thrombi occur in TTP.

\section{What is the role of $v W F$ ?}

It is a glycoprotein in the plasma made of several multimers which are connected by disulfide bonds. The molecular weight could reach millions of Daltons. The vWF serves as a carrier for factor VIII. It also has a major role in mediating platelet adhesion and aggregation at site of endothelial Injury. It binds to platelet glycoprotein receptors $1 \mathrm{~b} /$ IX/V and $\alpha \mathrm{IIb} \beta 3$. It is synthesized in endothelial cells and stored in Weibel-Palade bodies as multimers. Upon activation the multimer will be secreted and anchored to the surface of the endothelial cell where it interacts with the platelet glycoreceptors causing aggregation and thrombi formation.

\section{TTP and ADAMTS-13}

TTP is due to the inability to process the ultra large vWF multimers. Now it is believed that patients with TTP lack an enzyme that is responsible for the cleavage of these ULVWF multimers. ADAMTS-13 is one of the 19 ADAMTS metalloprotease enzymes. This enzyme usually avoids the entrance of large vWF multimers into the circulation by cleaving the peptide bonds of the monomeric subunit at the level of $842-843$ between tyrosine and methionine. Thus, it has a physiological role of preventing platelet thrombi formation.

ADAMTS-13 is produced mainly in the hepatocytes. The gene is located on chromosome $9 \mathrm{q} 34$. It is a member of zinc and calcium dependent proteases. Any defect in ADAMTS-13 can lead to different clinical presentations of TTP.

Patients with familial and acquired TTP have plasma ADAMTS-13 levels $<5 \%$ of normal. As a result the secreted vWF multimers remain attached to the endothelial cell surface in long strings. More platelets will adhere to the unusual large multimer due to their activated glycoprotein Ibis/IIIa complexes leading to occlusive thrombi.

\section{The ADAMTS13 gene}

ADAMTS13 cleaves vWF polypeptide whenever this normally cryptic bond is rendered accessible by circulatory shear stress. This rendered endothelial vWF polymer into smaller multimers that are conformationally less flexible and less adhesive. In the absence of ADAMTS13 vWF multimers are conformationally unfolded but are not cleaved. This results in accumulation of hyperactive forms of vWF leading to platelet aggregation and microvascular thrombosis.

Clinically, platelet thrombosis does not occur when ADAMTS13 is greater than $10 \%$ of normal values. But there is no lower threshold level for ADAMTS13 below which micorvascaulr thrmbosis invariabley ocurs. Various factors play a role in determining the level of ADAMTS13 prtoien including circulatory shear stress, platelt receptor levels, vWF and other unknown factors.

\section{Laboratory Findings}

The most important hematological parameters for the diagnosis of TTP/HUS are thrombocytopenia and microangiopathic hemolytic anemia. Thrombocytopenia is usually more severe in cases without predominant renal involvement; the platelet count are usually as low as $<20,000 / \mathrm{mm} 3$ at presentation [8]. Microangiopathic Hemolytic Anemia (MAHA) is a major diagnostic criterion for TTP and it is defined by the presence of schistocytes in the peripheral smear along with evidence of hemolysis. It was initially not clear as to how many schistocytes are required in peripheral smear for the diagnosis of TTP induced MAHA. But now it is concluded that more than $1 \%$ schistocytes, in the absence of other causes of thrombotic angiopathies, is highly suggestive of TTP-HUS [9] (Figure 1). Features of hemolytic anemia include increased reticulocyte count, increased lactate dehydrogenase levels $(\mathrm{LDH})$, elevated indirect bilirubin; low serum haptoglobin levels with the intravascular hemolysis and increased levels of free plasma hemoglobin in severe cases [10-12]. Direct antiglobulin test is usually negative suggestive of the non-immune hemolytic process in TTP-HUS except in cases of neuraminidase-associated HUS $[13,14]$. Proteinuria, microscopic hematuria, granular or red cell casts may be seen with renal involvement. TTP rarely presents with severe renal failure and anuria, although up to $60 \%$ of TTP cases have renal dysfunction $[8,15]$.

Measurement of ADAMTS 13 is necessary in the work up for TTP but it is not a diagnostic criterion because the levels may be normal in many patients that otherwise have all the features of TTP $[16,17]$. ADAMTS 13 levels less than 10\% is considered specific for TTP, it can often be low in liver failure, sepsis, chronic kidney disease, connective tissue disorders, pregnancy and various other inflammatory conditions but the levels are not as low as less than $10 \%$ of the normal in these 


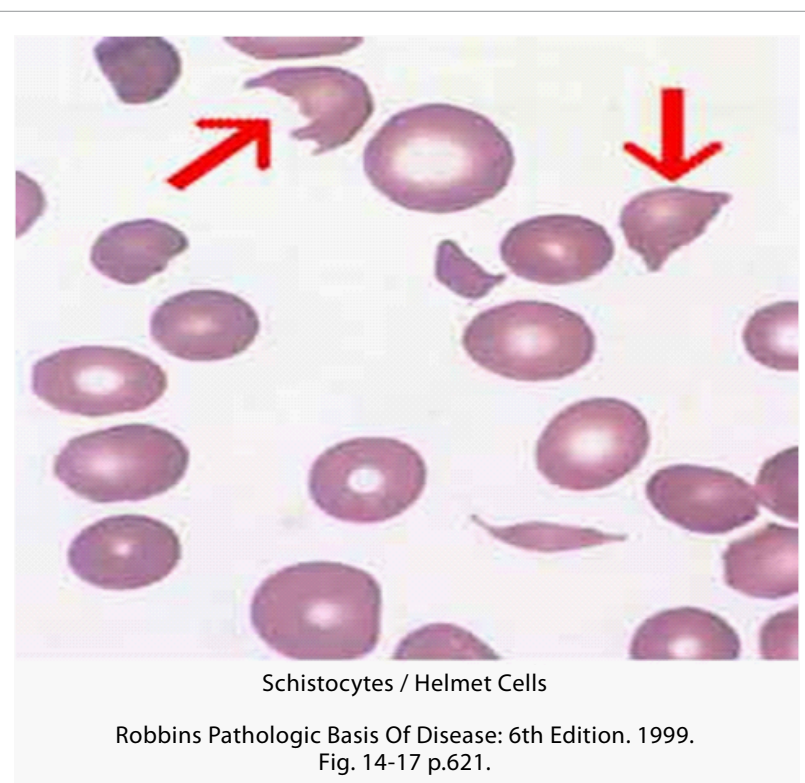

Figure 1: Showing schistocytes in peripheral smear

conditions [18-20]. Patients with persistent anti-ADAMTS13 antibodies or undetectable levels of ADAMTS13 are at a higher risk for recurrence [16]. However, measurement of ADAMTS 13 during the remission is not routinely recommended [21]. The low levels are indicative of either congenital or acquired deficiency. This acquired deficiency can be a result of antibodies or inhibitors to ADAMTS 13. There are many assays used to detect these antibodies but there is no standardized and reliable assay widely available [15]. In cases of suspected diarrhea positive HUS, the diagnosis is based on detection of E.coli 0157:H7 or Shiga-toxin producing bacteria on sorbitol-MacConkey agar [22]. There are serological tests to detect the antibodies against the toxin and they are more sensitive compared to cultures but so far they are used only in research laboratories [23,24]. Patients with suspected atypical diarrhoea negative HUS can be tested for complement regulatory proteins like Complement Factor $\mathrm{H}(\mathrm{CFH})$, Complement Factor I (CFI) and Membrane Receptor Protein (MCP). Tests to identify genetic mutations for these complements are usually performed when the levels of the complements are low [25].

\section{Treatment}

\section{Plasma therapy}

Plasma therapy remains the mainstay of treatment. A delay in the initiation of plasma therapy can be fatal. Plasma therapy has improved survival in more than $80-90 \%$ of the patients [26]. It is often difficult to make a diagnosis of TTP or HUS at presentation and thus it is recommended to start plasma therapy in all adult patients with suspected TTP or HUS (thrombocytopenia, microangiopathic hemolytic anemia with or without fever, neurological, renal manifestations and in the absence of any other causes of thrombotic angiopathies) [21,27]. If cultures or serology come back positive for E.coli or toxin producing diarrhoea and the patient does not have severe neurological manifestations then plasma therapy can be discontinued [27]. In such cases, treatment would be supportive similar to diarrhoea positive HUS cases in children. But for all others with TTP plasma therapy should be continued unless another etiology for the thrombotic angiopathy is detected and confirmed. Plasma therapy can be in the form of plasma exchange, plasma infusion, cryoprecipitate or solvent-detergent treated plasma. There are many studies to determine the efficacy of plasma exchange versus infusion but there is no proven benefit of one over the other [28]. Nonetheless, plasma exchange is preferred because larger amount of plasma can be given to the patient without fluid overload and it also allows more rapid removal of anti-ADMATS 13 antibodies compared to plasma infusion but there are no studies to prove this benefit [27]. The goal of plasmapheresis is to exchange at least 1 to 2 plasma volumes per day $(40-50 \mathrm{ml} / \mathrm{kg})$ [29,30]. Solventdetergent treated plasma has lower rates of allergic reactions, however; ADAMTS13 concentration in solvent-treated plasma is $20 \%$ lower than that of fresh frozen plasma [31,32]. Efficacy of the plasma therapy is assessed by monitoring the LDH, platelet count and neurological signs. The therapy should be continued for at least two to three days after the platelet count and LDH are normal [33,34].

Plasma therapy is also beneficial in some secondary forms of TTP like ticlopidine or clopidogrel induced TTP or pregnancy associated TTP but its role in chemotherapy associated TTP and bone marrow transplantation associated TTP has not resulted in improved outcome $[35,40]$.

\section{Antiplatelet therapy}

Antiplatelet agents are not recommended in the treatment of TTP. It does not change the outcome and survival and may even increase the chance of bleeding in some cases with severe thrombocytopenia $[41,42]$.

\section{Corticosteroids, immunosuppressive therapy and monoclo- nal antibodies}

Corticosteroids as the sole agent to prevent recurrences of TTP have not proven to be of benefit. However, patients with ADAMTS 13 deficiency are started on steroids alone as recommended by many experts $[43,44]$. Combination of steroids with immunosuppressive drugs like vincristine, azathioprine and monoclonal antibody rituximab is used to prevent relapse in atypical HUS causes deficiency of complement proteins $[45,46]$. Rituximab by itself has been shown to significantly reduce the recurrence in cases of TTP caused by antiADAMTS13 antibodies. It has been used in patients that have failed the combination of plasmapheresis plus steroids. It can also be used as prophylaxis to prevent relapse in TTP patients with presence of anti-ADAMTS13 antibodies [47-50]. Anecdotal case reports with eculizumab, anti-C5 monoclonal antibody, in the use atypical HUS have been reported but clinical trials have yet to prove its role and benefit $[51,52]$.

\section{Splenectomy}

Previously, it was considered in conjunctions with other modes of treatment and induced remission in 50\% cases but now it is mainly reserved for cases that have not responded to plasmapheresis and immunosuppressive treatment $[42,53]$.

\section{Transplantation}

Patients that progress to end stage renal disease are good candidates for renal transplantation but HUS can recur in the renal allograft [54]. This recurrence in the renal allograft may be avoided if liver transplantation is also done. Liver produces the complements implicated in the pathophysiology of recurrent HUS. But, this is not without its own downfalls and patients need to be carefully selected for isolated renal versus renal and liver transplantation in case HUS cases caused by deficiency of complements and membrane cofactor protein $[55,56]$. 
Citation: Saifan C, Nasr R, Mehta S, Acharya PS, El-Sayegh S (2012) Thrombotic Thrombocytopenic Purpura. J Blood Disord Transfus S3:001. doi:10.4172/2155-9864.S3-001

\section{References}

1. Vesely SK, George JN, Lämmle B, Studt JD, Alberio L, et al. (2003) ADAMTS13 activity in thrombotic thrombocytopenic purpura-hemolytic uremic syndrome: relation to presenting features and clinical outcomes in a prospective cohort of 142 patients. Blood 102: 60-68

2. Waters AM, Kerecuk L, Luk D, Haq MR, Fitzpatrick MM, et al. (2007) Hemolytic uremic syndrome associated with invasive pneumococcal disease: the United kingdom experience. J Pediatr 151: 140-144

3. Tarr PI, Gordon CA, Chandler WL (2005) Shiga-toxinproducing Escherichia coli and haemolytic uraemic Lancet 365: 1073-1086.

4. Hovinga JA, Vesely SK, Terrell DR, La"mmle B, George JN (2010) Survival and relapse in patients with thrombotic thrombocytopenic purpura. Blood 115 1500-1511.

5. Terrell DR, Williams LA, Vesely SK, Lämmle B, Hovinga JA, et al. (2005) The incidence of thrombotic thrombocytopenic purpura-hemolytic uremic syndrome: all patients, idiopathic patients, and patients with severe ADAMTS-13 deficiency. J Thromb Haemost 3: 1432-1436.

6. Bukowski RM (1982) Thrombotic thrombocytopenic purpura: a review. Prog Hemost Thromb 6: 287-337.

7. Amorosi EL, Ultmann JE (1966) Thrombotic thrombocytopenic purpura: report of 16 cases and review of the literature. Medicine 45: 139-159.

8. Rock G, Kelton JG, Shumak KH, Buskard NA, Sutton DM, et al. (1998) Laboratory abnormalities in thrombotic thrombocytopenic purpura. Canadian Apheresis Group. Br J Haematol 103: 1031-1036.

9. Burns ER, Lou Y, Pathak A (2004) Morphologic diagnosis of thrombotic thrombocytopenic purpura. Am J Hematol 75: 18-21.

10. Noris M, Remuzzi G (2009) Atypical hemolytic-uremic syndrome. N Engl J Med 361: 1676-1687

11. George JN (2006) Clinical practice. Thrombotic thrombocytopenic purpura. N Engl J Med 354: 1927-1935.

12. Ruggenenti P, Galli M, Remuzzi G (2001) Hemolytic uremic syndrome, thrombotic thrombocytopenic purpura, and antiphospholipid antibody syndromes. Immunologic renal diseases. Lippincott Williams \& Wilkins, Philadelphia.

13. McGraw ME, Lendon M, Stevens RF, Postlethwaite RJ, Taylor CM (1989) Haemolytic uraemic syndrome and the Thomsen Friedenreich antigen. Pediatr Nephrol 3: 135-139.

14. Rock GA, Shumak KH, Buskard NA, Blanchette VS, Kelton JG, et al. (1991) Comparison of plasma exchange with plasma infusion in the treatment of thrombotic thrombocytopenic purpura. Canadian Apheresis Study Group. N Engl J Med 325: 393-397.

15. Hovinga JA, Vesely SK, Terrell DR, Lammle B, George JN (2010) Survival and relapse in patients with thrombotic thrombocytopenic purpura. Blood 115: 1500-1511.

16. Vesely SK, George JN, Lammle B, Studt JD, Alberio L, et al. (2003) ADAMTS13 activity in thrombotic thrombocytopenic purpura-hemolytic uremic syndrome: relation to presenting features and clinical outcomes in a prospective cohort of 142 patients. Blood 102: 60-68.

17. Tsai HM (2003) Is severe deficiency of von Willebrand factor cleaving protease (ADAMTS-13) specific for thrombotic thrombocytopenic purpura? Yes. J Thromb Haemost 1: 625-631.

18. Mannucci PM, Canciani T, Forza I, et al. (2001) Changes in health and disease of the metalloprotease that cleaves von Willebrand factor. Blood 98: 2730-2735.

19. Mannucci PM, Vanoli M, Forza I, Canciani MT, Scorza R (2003) von Willebrand factor cleaving protease (ADAMTS-13) in 123 patients with connective tissue diseases (systemic lupus erythematosus and systemic sclerosis). Haematologica 88: 914-918.

20. George JN (2010) How I treat patients with thrombotic thrombocytopenic purpura: 2010. Blood 116: 4060-4069.

21. Peyvandi F, Palla R, Lotta LA, Mackie I, Scully MA, et al. (2010) ADAMTS-13 assays in thrombotic thrombocytopenic purpura. J Thromb Haemost 8: 631640

22. Boyce TG, Swerdlow DL, Griffin PM (1995) Escherichia coli 0157:H7 and the hemolytic uremic syndrome. N Engl J Med 333: 364-368.

23. Banatvala N, Griffin PM, Greene KD, Barrett TJ, Bibb WF, et al. (2001) The United States national prospective hemolytic uremic syndrome study: microbiologic, serologic, clinical and epidemiologic findings. J Inf Dis 183: 1063-1070.

24. Tarr PI, Neill MA, Clausen CR, Watkins SL, Christie DL, et al. (1990) Escherichia coli 0157:H7 and the hemolytic uremic syndrome: Importance of early cultures in establishing the etiology. J Inf Dis 162: 553-556.

25. Brady HR, Wilcox CS (2008) Therapy in Nephrology and Hypertension: A Companion to Brenner and Rector's The Kidney. (3rdedn), Saunders Elsevier, Philadelphia.

26. Bell WR, Braine HG, Ness PM, Kickler TS (1991) Improved survival in thrombotic thrombocytopenic purpura-hemolytic uremic syndrome. Clinical experience in 108 patients. N Engl J Med 325: 398-403.

27. Clark WF, Hildebrand A (2011) Attending Rounds: Microangiopathic hemolytic anemia with Renal Insufficiency. Clin J Am Soc Nephrol 7: 342-347.

28. Brunskill SJ, Tusold A, Benjamin S, Stanworth SJ, Murphy MF (2007) A systematic review of randomized controlled trials for plasma exchange in the treatment of thrombotic thrombocytopenic purpura. Transfus Med 17: 17-35.

29. Allford SL, Hunt BJ, Rose P, Machin SJ, Haemostasis and Thrombosis Task Force, et al. (2003) Guidelines on the diagnosis and management of the thrombotic microangiopathic haemolytic anaemias. $\mathrm{Br} \mathrm{J}$ Haematol 120: 556573

30. George JN (2007) Evaluation and management of patients with thrombotic thrombocytopenic purpura. J Intensive Care Med 22: 82-91.

31. Scully M, Longair I, Flynn M, Berryman J, Machin SJ (2007) Cryosupernatan and solvent detergent fresh-frozen plasma (Octaplas) usage at a single centre in acute thrombotic thrombocytopenic purpura. Vox Sang 93: 154-158.

32. Heger A, Kannicht C, Romisch J, Svae TE (2006) Normal levels of ADAMTS13 and factor $\mathrm{H}$ are present in the pharmaceutically licensed plasma for transfusion (Octaplas) and in the universally applicable plasma (Uniplas) in development. Vox Sang 92: 206-212.

33. Basic-Jukic N, Kes P, Bubic-Filipi L, Brunetta B (2007) Treatment of thrombotic microangiopathies with plasma exchange. Hematology 12: 63-67.

34. George JN (2007) Evaluation and management of patients with thrombotic thrombocytopenic purpura. J Intensive Care Med 22: 82-91.

35. Zakarija A, Bandarenko N, Pandey DK, Auerbach A, Raisch DW, et al. (2004) Clopidogrel-associated TTP: An update of pharmacovigilance efforts conducted by independent researchers, pharmaceutical suppliers, and the Food and Drug Administration. Stroke 35: 533-537.

36. Ezra Y, Rose M, Eldor A (1996) Therapy and prevention of thrombotic thrombocytopenic purpura during pregnancy: A clinical study of 16 pregnancies Am J Hematol 51: 1-6.

37. von Baeyer H (2002) Plasmapheresis in thrombotic microangiopathyassociated syndromes: Review of outcome data derived from clinical trials and open studies. Ther Apheresis 6: 320-328.

38. Fuge R, Bird JM, Fraser A, Hart D, Hunt L, et al. (2001) The clinical features, risk factors and outcome of thrombotic thrombocytopenic purpura occurring after bone marrow transplantation. Br J Haematol 113: 58-64.

39. George JN, Li X, McMinn JR, Terrell DR, Vesely SK, et al. (2004) Thrombotic thrombocytopenic purpura-hemolytic uremic syndrome following allogeneic HPC transplantation; a diagnostic dilemma. Transfusion 44: 294-304.

40. Batts ED, Lazarus HM (2007) Diagnosis and treatment of transplantationassociated thrombotic microangiopathy: Real progress or are we still waiting Bone Marrow Transplant 40: 709-719.

41. Bell WR, Braine HG, Ness PM, Kickler TS (1991) Improved survival in thrombotic thrombocytopenic purpura-hemolytic uremic syndrome. $\mathrm{N}$ Engl $J$ Med 325: 398-403.

42. Kwaan HC, Soff GA (1997) Management of thrombotic thrombocytopenic purpura and hemolytic uremic syndrome. Semin Hematol 34: 159-166.

43. George JN (2000) How I treat patients with thrombotic thrombocytopenic purpura-hemolytic uremic syndrome. Blood 96: 1223-1229.

44. Allford SL, Hunt BJ, Rose P, Machin SJ, Haemostasis and Thrombosis Task 
Citation: Saifan C, Nasr R, Mehta S, Acharya PS, El-Sayegh S (2012) Thrombotic Thrombocytopenic Purpura. J Blood Disord Transfus S3:001. doi:10.4172/2155-9864.S3-001

Page 5 of 5

Force, et al. (2003) Guidelines on the diagnosis and management of the thrombotic microangiopathic haemolytic anaemias. $\mathrm{Br} \mathrm{J}$ Haematol 120: 556573

45. Skerka C, Józsi M, Zipfel PF, Dragon-Durey MA, Fremeaux-Bacchi V (2009) Autoantibodies in haemolytic uraemic syndrome (HUS). Thromb Haemost 101: 227-232.

46. Józsi M, Strobel S, Dahse HM, Liu WS, Hoyer PF, et al. (2007) Anti factor $H$ autoantibodies block $\mathrm{C}$-terminal recognition function of factor $\mathrm{H}$ in hemolytic uremic syndrome. Blood 110: 1516-1518.

47. Scully M, Cohen H, Cavenagh J, Benjamin S, Starke R, et al. (2007) Remission in acute refractory and relapsing thrombotic thrombocytopenic purpura following rituximab is associated with a reduction in IgG antibodies to ADAMTS-13. Br J Haematol 136: 451-461.

48. Fakhouri F, Vernant JP, Veyradier A, Wolf M, Kaplanski G, et al. (2005) Efficiency of curative and prophylactic treatment with rituximab in ADAMTS13deficient thrombotic thrombocytopenic purpura: a study of 11 cases. Blood 106 1932-1937.

49. Bresin E, Gastoldi S, Daina E, Belotti D, Pogliani E, et al. (2009) Rituximab as pre-emptive treatment in patients with thrombotic thrombocytopenic purpura and evidence of anti-ADAMTS13 autoantibodies. Thromb Haemost 101: 233238.
50. Galbusera M, Bresin E, Noris M, Gastoldi S, Belotti D, et al. (2005) Rituximab prevents recurrence of thrombotic thrombocytopenic purpura: a case report. Blood 106: 925-928.

51. Gruppo RA, Rother RP (2009) Eculizumab for congenital atypical hemolyticuremic syndrome. N Engl J Med 360: 544-546.

52. Nürnberger J, Philipp T, Witzke O, Opazo Saez A, Vester U, et al. (2009) Eculizumab for atypical hemolytic-uremic syndrome. N Engl J Med 360: 542 544.

53. Crowther MA, Heddle N, Hayward CP, Warkentin T, Kelton JG, et al. (1996) Splenectomy done during hematologic remission to prevent relapse in patients with thrombotic thrombocytopenic purpura. Ann Intern Med 125: 294-296.

54. Ruggenenti P (2002) Post-transplant hemolytic-uremic syndrome. Kidney Int 62: 1093-1104.

55. Saland JM, Ruggenenti P, Remuzzi G, Consensus Study Group (2009) Liverkidney transplantation to cure atypical hemolytic uremic syndrome. J Am Soc Nephrol 20: 940-949.

56. Jalanko H, Peltonen S, Koskinen A, Puntila J, Isoniemi H, et al. (2008) Successful liver-kidney transplantation in two children with aHUS caused by a mutation in complement factor $\mathrm{H}$. Am J Transplant 8: 216-221. 